\title{
Avaliação do ambiente acadêmico e qualidade de vida dos estudantes de Medicina do ciclo básico da Universidade de Uberaba
}

Evaluation of the academic environment and quality of life Medical students in the basic cycle of the University of Uberaba

Evaluación del entorno académico y de la calidad de vida de los estudiantes de Medicina de ciclo básico de la Universidad de Uberaba

Recebido: 20/09/2021 | Revisado: 29/09/2021 | Aceito: 05/10/2021 | Publicado: 07/10/2021

Gabriel Martins Da Silva
ORCID: https://orcid.org/0000-0001-9691-105X
Universidade de Uberaba, Brasil
E-mail: gabriel.gmsilva7@gmail.com
Lisandra Nogueira Garcia
ORCID: https://orcid.org/0000-0001-8281-120X
Universidade de Uberaba, Brasil
E-mail: lisandra_lg@ hotmail.com
Luís Máximo De Araújo Junior
ORCID: https://orcid.org/0000-0001-5469-6654
Universidade de Uberaba, Brasil
E-mail: 1.maximo@ hotmail.com
Luisa Boldrin Cardoso De Souza
ORCID: https://orcid.org/0000-0001-7588-999X
Universidade de Uberaba, Brasil
E-mail: luisaboldrin20@gmail.com
Maria Vilaça Omena Da Silva
ORCID: https://orcid.org/0000-0001-8852-6477
Universidade de Uberaba, Brasil
E-mail: mariaaomena@hotmail.com
Douglas Reis Abdalla
Doula
ORCID: https://orcid.org/0000-0002-6971-1201
Faculdade de Talentos Humanos, Brasil
E-mail: drabdalla@facthus.edu.br
Renato Humberto Fabri
ORCID: https://orcid.org/0000-0003-2843-8154
Universidade de Uberaba, Brasil
E-mail: Renato.fabri@uniube.br

\begin{abstract}
Resumo
O curso de medicina exige preparo intelectual e emocional. Ao ingressar no curso é necessária dedicação, intensa carga de trabalho e inúmeras horas de estudo, além da intensa cobrança. $\mathrm{O}$ objetivo deste estudo é compreender o ambiente acadêmico e qualidade de vida dos estudantes de medicina do ciclo básico da Universidade de Uberaba. Trata-se de um estudo quantitativo prospectivo de caráter descritivo observacional transversal. Foram selecionados alunos do ciclo básico do curso de medicina da Universidade de Uberaba por amostragem probabilística aleatória simples. A percepção a respeito do ambiente de ensino foi analisado através do questionário DREEM. A qualidade de vida dos estudantes foi avaliada pelo questionário WHOQOL-BREF. Responderam a pesquisa 218 (77,3\%) alunos, sendo 63,8\% mulheres e $36,2 \%$ homens. O questionário socioeconômico mostrou que 60,6\% dos alunos têm idade entre 16 e 20 anos e 39,9\% moram com os pais. Apenas 13,8\% fazem acompanhamento psicológico. Pelo questionário DREEM a percepção dos discentes foi mais positiva nos domínios aprendizado, professores, acadêmicos, atmosfera e sociais. O questionário WHOQOL-BREF avaliou quatro domínios. O domínio físico apresentou média de 3,43, psicológico de 21,31, social de 3,79 e ambiental de 3,84. A percepção dos discentes em relação ao ambiente acadêmico foi mais positiva do que negativa, mas necessitando de melhorias. A qualidade de vida dos estudantes foi considerada positiva quanto aos aspectos físicos e ambiental, e apontada como negativa nas questões físicas e psicológicas. Estudos mais abrangentes poderiam contribuir para o aprimoramento de intervenções com intuito de melhorar o ambiente educacional.
\end{abstract}

Palavras-chave: Estudantes; Medicina; Qualidade de vida. 


\begin{abstract}
The medical course requires intellectual and emotional preparation. When entering the course, dedication, intense workload and countless hours of study are required, in addition to intense pressure. The aim of this study is to understand the academic environment and quality of life of basic cycle medical students at the University of Uberaba. This is a prospective quantitative study of a descriptive observational cross-sectional nature. Students from the basic cycle of the medical course at the University of Uberaba were selected by simple random probability sampling. The perception regarding the teaching environment was analyzed using the DREEM questionnaire. The quality of life of the students was evaluated by the WHOQOL-BREF questionnaire. The survey was answered by $218(77.3 \%)$ students, $63.8 \%$ female and $36.2 \%$ male. The socioeconomic questionnaire showed that $60.6 \%$ of the students are between 16 and 20 years old, and $39.9 \%$ live with their parents. Only $13.8 \%$ receive psychological counseling. According to the DREEM questionnaire, the students' perception was more positive in the learning, teachers, academic, atmosphere, and social domains. The WHOQOL-BREF questionnaire evaluated four domains. The physical domain had a mean of 3.43, psychological 21.31, social 3.79, and environmental 3.84. The perception of the students in relation to the academic environment was more positive than negative, but in need of improvement. The students' quality of life was considered positive regarding the physical and environmental aspects, and pointed out as negative in the physical and psychological issues. More comprehensive studies could contribute to the improvement of interventions to improve the educational environment.
\end{abstract}

Keywords: Students; Medicine; Quality of life.

\title{
Resumen
}

El curso de medicina exige una preparación intelectual y emocional. Al entrar en el curso, se requiere dedicación, una intensa carga de trabajo e innumerables horas de estudio, además de una intensa presión. El objetivo de este estudio es conocer el ambiente académico y la calidad de vida de los estudiantes de medicina del ciclo básico de la Universidad de Uberaba. Se trata de un estudio cuantitativo prospectivo de carácter descriptivo observacional transversal. Los estudiantes del ciclo básico del curso de medicina de la Universidad de Uberaba fueron seleccionados por muestreo probabilístico aleatorio simple. La percepción sobre el entorno de la enseñanza se analizó mediante el cuestionario DREEM. La calidad de vida de los estudiantes se evaluó mediante el cuestionario WHOQOL-BREF. Un total de 218 $(77,3 \%)$ estudiantes respondieron a la encuesta, siendo el 63,8\% mujeres y el 36,2\% hombres. El cuestionario socioeconómico mostró que el 60,6\% de los estudiantes tiene entre 16 y 20 años y el 39,9\% vive con sus padres. Sólo el 13,8\% recibe asesoramiento psicológico. Según el cuestionario DREEM, la percepción de los alumnos fue más positiva en los ámbitos de aprendizaje, profesores, académico, ambiente y social. El cuestionario WHOQOL-BREF evaluó cuatro dominios. El dominio físico mostró una media de 3,43, el psicológico de 21,31, el social de 3,79 y el ambiental de 3,84. La percepción de los estudiantes en relación con el entorno académico fue más positiva que negativa, pero necesita mejorar. La calidad de vida de los estudiantes se consideró positiva en los aspectos físicos y ambientales, y se señaló como negativa en las cuestiones físicas y psicológicas. Estudios más exhaustivos podrían contribuir a mejorar las intervenciones para mejorar el entorno educativo.

Palabras clave: Estudiantes; Medicina; Calidad de vida.

\section{Introdução}

O curso de medicina é um dos mais almejados pelos estudantes de ensino médio e cursos pré-vestibulares. O caminho para se alcançar esse objetivo exige preparo intelectual e emocional para lidar com diversas situações como, imposições familiares, necessidades de autoafirmação, privação de prazeres, pressão por parte de colegas e professores, bem como, a autocobrança por bons resultados. No entanto, conseguir alcançar o famigerado sonho nem sempre é sinônimo de tranquilidade. Ao ingressar no ensino superior, são necessárias muitas horas de dedicação para corresponder às necessidades de uma boa formação teórico-científico-prática. A cobrança agora ganha o cunho do mercado de trabalho e a busca pela excelência passa a confrontar novamente o agora acadêmico (Feodrippe et al., 2013).

Essa transição do ensino médio para a universidade é um período decisivo da evolução com inúmeros desafios que exigem adaptações, em consequência, gera um desgaste biopsiconoético que influencia desfavoravelmente a qualidade de vida dos envolvidos (Borine et al., 2015). Não obstante, a qualidade de vida pode ser definida como compreensão do indivíduo quanto a sua posição na vida no âmbito cultural e sistema de valores nos quais ele está inserido, principalmente no que diz respeito aos objetivos, anseios e padrões (The World Health Organization Quality of Life assessment [WHOQOL], 1995). 
A qualidade de vida influencia o estado de saúde e o desempenho acadêmico do aluno. As instituições de educação estão modificando gradativamente a forma de ensino devido a percepção dessa influência, de forma que a aprendizagem do aluno não se faz mais isoladamente, mas necessita de um ambiente adequado e de boa qualidade de vida (Sarwar et al., 2019).

A principal forma de garantir a qualidade de vida das pessoas é cuidar integralmente do indivíduo na sua condição física, psíquica e social. (Olivares et al., 2015).

O ambiente acadêmico é constituído por questões físicas, emocionais e intelectuais. A característica desse ambiente influencia a vida do aluno afetando pontos como o aprendizado, incentivo para realizar as atividades, as emoções e a responsabilidade com que realiza suas tarefas. Um clima satisfatório ao acadêmico reflete nos pacientes que são atendidos e assistidos (Bakhshialiabad et al., 2019).

No entanto, o sistema de ensino muitas vezes choca-se com essa premissa ignorando as particularidades de cada aluno. É notório que desde a entrada no ensino superior à conclusão do curso, ocorrem diversas mudanças na vida dos universitários. Dessa maneira, esse é um período conturbado com inúmeros desafios e incertezas que podem desencadear problemas de ordem psíquica (Costa \& Moreira, 2016).

A elevada carga horária, o abundante número de trabalhos acadêmicos, problemas de ordem financeira, mudança de cidade, distância da família e as dificuldades interpessoais encontradas no novo âmbito são desafios a serem enfrentados pelo estudante. Dentro desse contexto, é possível inferir que os alunos dos primeiros anos da universidade são os mais vulneráveis, já que, nessa fase, os estudantes apresentam maior susceptibilidade ao aparecimento de sintomas depressivos e ansiosos, devido às dificuldades de adaptação à nova vida. Nessa perspectiva, os índices de ansiedade e depressão em universitários encontramse elevados, sendo considerados superiores aos encontrados na população geral (Ibrahim et al., 2013). Nesse sentido, é comum recém ingressados no ensino superior referirem mudanças de hábitos, como pouco lazer, alimentação inadequada, sedentarismo, privação de sono, e queixam-se de sintomas gerais, como insônia, cefaleia, dores lombares, ansiedade, arritmia e sintomas gastrointestinais, como diarreia, pirose, epigastralgia e refluxo. Esse conjunto de sintomas, que podem aparecer agrupados ou separados interferem diretamente na desqualificação da qualidade de vida desses indivíduos (Mendonça et al., 2019). Sob essa perspectiva, tais adversidades podem prejudicar a performance cognitiva do aluno e suas relações interpessoais no meio acadêmico, e de forma mais ampla, podem afetar a qualidade de sua formação, bem como a futura carreira profissional (Costa \& Moreira, 2016).

Dessa maneira, estratégias como programas de suporte e apoio aos acadêmicos são cruciais para auxiliá-los nos enfrentamentos cotidianos de sua formação (Peres et al., 2004). Estímulos à prática de exercícios físicos, socialização e cuidados com a saúde resultam em significativa otimização da vida acadêmica com uma melhor adaptação e ajustamento emocional, principalmente entre os integrantes do primeiro ano de curso (Pereira et al., 2017). Além disso, o reconhecimento de possíveis lacunas no processo ensino-aprendizagem proporciona novas possibilidade de reavaliação do currículo médico, vínculo entre alunos, professores, identificar situações de risco para a saúde física e mental, além de desenvolver sistemas e departamentos de apoio ao aluno (Cunha et al., 2017). Assim, é importante que as instituições acadêmicas tenham uma visão integrada do aluno de forma a estimular o acadêmico para o desenvolvimento de relações sociais e o próprio crescimento pessoal (Yoo \& Kim, 2019).

É possível perceber como a qualidade de vida do aluno está sujeita ao ambiente universitário em que vive, afetando desde seu desempenho até suas relações pessoais e sociais. Assim, é importante avaliar e correlacionar como esse ambiente educacional interfere no bem-estar do estudante e quais sãos os fatores de uma boa qualidade de vida que mais são afetados. Isso possibilitará traçar métodos para transformar o meio educacional e melhorar bem-estar do estudante de medicina.

O objetivo deste estudo é avaliar o ambiente acadêmico e qualidade de vida dos estudantes de medicina do ciclo básico da Universidade de Uberaba. 


\section{Metodologia}

Trata-se de um estudo quantitativo prospectivo de caráter descritivo observacional transversal. O estudo foi aprovado pelo Comitê de Ética em Pesquisa da Universidade de Uberaba (Parecer n ${ }^{\circ}$ 3.430.274 - CAAE: 11717019.6.0000.5145).

O estudo se deu na Universidade de Uberaba (Uniube) - Campus Aeroporto, no município de Uberaba, Minas Gerais. Os dados foram coletados entre os meses de agosto e dezembro de 2019.

Participaram do estudo os alunos do ciclo básico ( $1^{\circ}$ ao $4^{\circ}$ período) devidamente matriculados no curso de Medicina da Uniube, selecionados por amostragem probabilística aleatória simples, convidados a compor um total de participantes proporcional ao total de alunos por turma.

Os alunos foram abordados durante seus respectivos horários de tutoria, com autorização da responsável pelo componente e em data e horário marcados com os tutores. A abordagem foi feita por quatro alunos previamente treinados para aplicação dos questionários e apresentação geral da pesquisa. Desse modo, fizeram parte do estudo os alunos em situação regular presentes no dia e horário marcado, e que após a elucidação sobre os objetivos da pesquisa, quiseram ser voluntários sem qualquer tipo de bonificação ou prejuízo.

Todos os voluntários preencheram o Termo de Consentimento Livre e Esclarecido (TCLE) e receberam uma cópia do termo assinada pelos responsáveis do estudo. Em seguida, os alunos preencheram os questionários socioeconômico, DREEM (Dundee Ready Education Environment Measurement) e WHOQOL-BREF obedecendo essa ordem, com um tempo limite préestabelecido de 45 minutos.

Para a caracterização da população do estudo, realizou-se o preenchimento do questionário socioeconômico que inclui questões a respeito de idade, sexo, peso, altura, estado civil, período da graduação em que se encontra, área que pretende especializar e há quanto tempo retornou de férias. Os acadêmicos também foram questionados em relação à participação em programas de bolsas ou descontos, com quem reside, se tem filhos, frequência da prática de atividades e realização de alguma terapia psicológica e/ou psiquiátrica ao longo da vida.

Com intuito de avaliar a percepção do acadêmico de medicina a respeito do ambiente de ensino, foi aplicado o questionário DREEM (Dundee Ready Education Environment Measurement) composto por 50 questões elencadas em cinco domínios: percepção da aprendizagem, sobre os professores, dos resultados acadêmicos, das relações sociais e do ambiente geral. Nove das frases eram negativas, sendo-lhes atribuída pontuação invertida (5 para a maior discordância e 1 para a maior concordância) (Guimaraes et al., 2015). A média da pontuação relacionada a cada domínio foi analisada de acordo com o guia prático de utilização do questionário DREEM proposto por McAleer e Roff (2001).

A fim de analisar a qualidade de vida dos estudantes, foi utilizado o questionário da OMS, WHOQOL-BREF, sua versão mais resumida. Essa versão, conta com 26 questões distribuídas em 4 dimensões, sendo: aspectos físicos, psicológicos, sociais e o ambiente de ensino. As respostas variam de 1 a 5 conforme o grau de satisfação, cujo o valor mínimo corresponde à "nada satisfeito" e o valor máximo à "muito satisfeito". As questões 3, 4 e 26 do questionário recebem pontuação invertida (Ferentz, 2017).

As respostas dos questionários DREEM e WHOQOL-BREF foram dadas em escala adaptada de Likert. Sendo que os escores do questionário DREEM recebem os seguintes valores: 1 para discordo totalmente (DT), 2 para discordo (D), 3 para indiferente (I), 4 para concordo (C) e 5 para concordo totalmente (CT). A soma dos escores varia de 50 a 250 e quanto maior o valor do escore melhor a percepção do indivíduo em relação ao ambiente e sua qualidade de vida.

Os dados foram analisados quanto à distribuição (Levene) e normalidade (Kolmogorov-Smirnov). Satisfeitas estas condições, foram realizados testes estatísticos paramétricos, como o teste de Análise de Variância (ANOVA). Para as comparações de frequências, porcentagens e mediana, foram utilizados testes estatísticos não-paramétricos. Todos os testes estatísticos adotaram nível de significância de 5\% $(\alpha=0,05)$ e foram realizados no software SPSS 17.1. 


\section{Resultados}

Em 2019-2 o curso de medicina da Universidade de Uberaba contava com o total de 601 alunos devidamente matriculados. Desses, 282 alunos compunham o ciclo básico e destes 218 (77,3\%) responderam à pesquisa e preencheram corretamente o Termo de Consentimento Livre e Esclarecido.

\subsection{Socioeconômico}

Conforme os dados obtidos com o questionário socioeconômico, existe um predomínio do sexo feminino em todos os períodos estudados, sendo $63,8 \%$ do total de pessoas que responderam os questionários (tabela 1). Entretanto, esse predomínio não é estatisticamente significativo ( $\mathrm{p}$-value $=0,856$ ).

No que se refere a idade, há um predomínio de alunos entre 16 e 20 anos (60,6\%) (Tabela 1), independente do período, sendo que nesse caso há uma diferença estatística ( $\mathrm{p}$-value $=0,001$ ). Isso reflete a média de idade com que as pessoas ingressam na faculdade.

A análise do estado civil demonstra que em todos os períodos existe predominância de acadêmicos solteiros (tabela 1), sem diferença estatística ( $p$-value $=0731$ ), em relação aos que estão namorando, casados e amasiados.

Outro dado que não constitui diferença estatística significante $(\mathrm{p}=0,677)$ é o predomínio de alunos que não tem filhos sobre os que possuem filhos, independente do período.

No quesito residência, há um predomínio entre morar com os pais ou sozinho e essa diferença é estatisticamente significante (p-value $=0,006$ ) em relação a morar com os amigos, outros ou parentes (tabela 1).

De acordo com os valores obtidos quanto a prática de atividade física, existe um predomínio de acadêmicos que praticam exercícios físicos de 3 a 5 vezes na semana no $1^{\circ}, 2^{\circ}$ e $4^{\circ}$ períodos (tabela 1). No $3^{\circ}$ período, predominam os estudantes que não praticam atividade física. Nesse âmbito não existe diferença estatística ( $\mathrm{p}$-value $=0,161$ ).

Quanto ao IMC, os valores são semelhantes em todos os períodos e não são estatisticamente significantes ( $\mathrm{p}$-value = $0,519)$.

No sistema de bolsas é possível observar que existe predomínio (tabela 1), estatisticamente insignificante (p-value = 0,107) de alunos que não possuem bolsa, em relação aqueles que possuem bolsa parcial, PROUNI e FIES.

A respeito do acompanhamento psicológico/psiquiátrico, há uma predominância de acadêmicos que nunca realizaram ou que já, mas não fazem atualmente, sobre aqueles que no momento estão em acompanhamento (tabela 1). Porém, não existe diferença estatística ( $\mathrm{p}$-value $=0,675$ ).

\subsection{Avaliação da percepção do ambiente de ensino}

No questionário DREEM, a média do domínio geral é de 170,47 (1,84). Baseado no guia de interpretação dos autores do questionário, pode-se compreender que a percepção dos estudantes em relação ao ambiente acadêmico em geral é mais positiva do que negativa. Nesse sentido, como representado na Figura 1 item A, há diferença estatísticas entre $1^{\circ}$ e $3^{\circ}$ e $1^{\circ}$ e $4^{\circ}$ períodos, bem como entre $2^{\circ}$ e $3^{\circ}$ e $2^{\circ}$ e $4^{\circ}$ períodos, $(p<0,0001)$. 
Tabela 1 - Avaliação socioeconômica.

\begin{tabular}{|c|c|c|c|c|c|c|}
\hline Variável & $1^{\circ}$ Período & $2^{\circ}$ Período & $3^{\circ}$ Período & $4^{\circ}$ Período & TOTAL & p-value \\
\hline Sexo & n (\%) & n (\%) & n (\%) & n $(\%)$ & n $(\%)$ & - \\
\hline Feminino & $36(16,5)$ & $41(18,8)$ & $28(12,8)$ & $34(15,6)$ & $139(63,8)$ & 0,856 \\
\hline Masculino & $17(7,8)$ & $23(10,6)$ & $19(8,7)$ & $20(9,2)$ & $79(36,2)$ & \\
\hline Idade & n $(\%)$ & n $(\%)$ & n (\%) & n (\%) & n $(\%)$ & - \\
\hline $16-20$ & $38(17,4)$ & $45(20,6)$ & $30(13,8)$ & $19(8,7)$ & $132(60,6)$ & 0,001 \\
\hline $21-25$ & $7(3,2)$ & $10(4,6)$ & $14(6,4)$ & $28(12,8)$ & $59(27,1)$ & \\
\hline $26-30$ & $2(0,9)$ & $4(1,8)$ & $1(0,5)$ & $2(0,9)$ & $9(4,1)$ & \\
\hline $31-35$ & $2(0,9)$ & $2(0,9)$ & $1(0,5)$ & $5(2,3)$ & $10(4,6)$ & \\
\hline $36-40$ & $1(0,5)$ & $2(0,9)$ & $1(0,5)$ & $0(0,0)$ & $4(1,8)$ & \\
\hline$>40$ & $3(1,4)$ & $1(0,5)$ & $0(0,0)$ & $0(0,0)$ & $4(1,8)$ & \\
\hline IMC & $\begin{array}{c}\mathbf{X}(\text { SEM }) \\
23,17(0,47)\end{array}$ & $\begin{array}{c}\mathbf{X}(\mathbf{S E M}) \\
22,95(0,41)\end{array}$ & $\begin{array}{c}\text { X (SEM) } \\
23,62(0,68)\end{array}$ & $\begin{array}{c}\text { X (SEM) } \\
22,59(0,36)\end{array}$ & $\begin{array}{c}\mathbf{X}(\text { SEM }) \\
23,06(0,24)\end{array}$ & 0,519 \\
\hline Estado Civil & n $(\%)$ & n (\%) & n $(\%)$ & n $(\%)$ & n (\%) & - \\
\hline Solteiro & $29(13,3)$ & $43(19,7)$ & $33(15,1)$ & $38(17,4)$ & $143(65,6)$ & 0,731 \\
\hline Namorando & $20(9,2)$ & $18(8,3)$ & $13(6)$ & $13(6)$ & $64(29,4)$ & \\
\hline Casado & $3(1,4)$ & $3(1,4)$ & $1(0,5)$ & $2(0,9)$ & $9(4,1)$ & \\
\hline Amasiado & $1(0,5)$ & $0(0)$ & $0(0)$ & $1(0,5)$ & $2(0,9)$ & \\
\hline Filhos & n (\%) & n (\%) & n (\%) & n (\%) & n (\%) & - \\
\hline Sim & $3(1,4)$ & $2(0,9)$ & $1(0,5)$ & $1(0,5)$ & $7(3,2)$ & 0,677 \\
\hline Não & $50(22,9)$ & $62(28,4)$ & $46(21,1)$ & $53(24,3)$ & $211(96,8)$ & \\
\hline Residência & n (\%) & n $(\%)$ & n $(\%)$ & n $(\%)$ & n $(\%)$ & - \\
\hline Pais & $25(11,5)$ & $28(12,8)$ & $16(7,3)$ & $18(8,3)$ & $87(39,9)$ & 0,006 \\
\hline Sozinho & $15(6,9)$ & $22(10,1)$ & $11(5,0)$ & $18(8,3)$ & $66(30,3)$ & \\
\hline Amigos & $4(1,8)$ & $2(0,9)$ & $14(6,4)$ & $12(5,5)$ & $32(14,7)$ & \\
\hline Outros & $7(3,2)$ & $5(2,3)$ & $1(0,5)$ & $4(1,8)$ & $17(7,8)$ & \\
\hline Parentes & $2(0,9)$ & $7(3,2)$ & $5(2,3)$ & $2(0,9)$ & $16(7,3)$ & \\
\hline Atividade Física & n (\%) & n $(\%)$ & n $(\%)$ & n (\%) & n $(\%)$ & - \\
\hline 1 a $2 x /$ semana & $17(7,8)$ & $15(6,9)$ & $10(4,6)$ & $16(7,3)$ & $58(26,6)$ & 0,161 \\
\hline 3 a $5 x /$ semana & $18(8,3)$ & $25(11,5)$ & $10(4,6)$ & $20(9,2)$ & $73(33,5)$ & \\
\hline$>5 x /$ semana & $2(0,9)$ & $5(2,3)$ & $5(2,3)$ & $7(3,2)$ & $19(8,7)$ & \\
\hline Não Pratica & $16(7,3)$ & $19(8,7)$ & $22(10,1)$ & $11(5)$ & $68(31,2)$ & \\
\hline Sistema de Bolsa & n $(\%)$ & $\mathrm{n}(\%)$ & n $(\%)$ & n $(\%)$ & n $(\%)$ & - \\
\hline Nenhuma & $47(21,6)$ & $58(26,6)$ & $40(18,3)$ & $48(22)$ & $193(88,5)$ & 0,107 \\
\hline Parcial & $4(1,8)$ & $2(0,9)$ & $0(0)$ & $4(1,8)$ & $10(4,6)$ & \\
\hline PROUNI & $2(0,9)$ & $4(1,8)$ & $7(3,2)$ & $2(0,9)$ & $15(6,9)$ & \\
\hline FIES & $0(0)$ & $0(0)$ & $0(0)$ & $0(0)$ & $0(0)$ & \\
\hline $\begin{array}{l}\text { Acompanhamento } \\
\text { Psicol./psiquiat. }\end{array}$ & n $(\%)$ & n $(\%)$ & n (\%) & n (\%) & n (\%) & - \\
\hline Sim, mas não atualmente & $21(9,6)$ & $25(11,5)$ & $20(9,2)$ & $23(10,6)$ & $89(40,8)$ & 0,675 \\
\hline Sim & $7(3,2)$ & $8(3,7)$ & $4(1,8)$ & $11(5)$ & $30(13,8)$ & \\
\hline Não & $25(11,5)$ & $31(14,2)$ & $23(10,6)$ & $20(9,2)$ & $99(45,4)$ & \\
\hline
\end{tabular}

Fonte: Autores (2021).

No domínio aprendizado, a média foi de 42,83(0,53). Esse resultado demonstra que a percepção dos acadêmicos quanto ao ensino na universidade é mais positiva. Então, os estudantes estão mais satisfeitos quanto a forma de ensino, com os conteúdos são administrados e quanto ao objetivo do curso. Foi notória a diferença estatística (Figura 1 , item B) entre $1^{\circ}$ e $3^{\circ}$ e o $1^{\circ}$ e $4^{\circ}$ períodos e entre $2^{\circ}$ e $3^{\circ}$ e o $2^{\circ}$ e $4^{\circ}$ períodos, $(p<0,0001)$.

Em relação a percepção dos alunos acerca dos professores, a média foi de $36,66(0,48)$ e indica que os docentes estão na direção certa, ou seja, há aprovação da forma de didática dos professores na transmissão dos conteúdos. No entanto, foi observado diferença estatística entre $1^{\circ}$ e $3^{\circ}$ e o $1^{\circ}$ e $4^{\circ}$ períodos e entre $2^{\circ}$ e $3^{\circ}$ e o $2^{\circ}$ e $4^{\circ}$ períodos (Figura 1 , item C) (p<0,0001). Portanto, 
apesar da visão mais positiva dos docentes, essa visão é menos concordante no $3^{\circ} \mathrm{e} 4^{\circ}$ períodos.

No âmbito da percepção dos resultados acadêmicos, a média foi de $25,85(0,38)$ e de acordo com o guia de interpretação utilizado, os alunos compreendem que o desempenho apresenta mais aspectos positivos do que negativos. Houve diferença estatística (Figura 1 , item D) entre $1^{\circ}$ e $4^{\circ}$ períodos e entre o $2^{\circ}$ e $3^{\circ}$ e o $2^{\circ}$ e o $4^{\circ}$ períodos, $(\mathrm{p}=0,0218)$.

A respeito da dimensão atmosfera, a percepção dos acadêmicos apresentou média de 42,02 (0,50), significando uma média alta que aponta para mais pontos positivos do que negativos. Nesse sentido, os alunos da universidade percebem o ambiente acadêmico como mais benéfico. Observou-se (Figura 1, item E) diferença estatística entre $1^{\circ} \mathrm{e} 3^{\circ}$ e o $1^{\circ}$ e $4^{\circ}$ períodos e entre 2 o e $3^{\circ}$ e o $2^{\circ}$ e $4^{\circ}$ períodos, $(p<0,0001)$.

O domínio social apresentação avaliação média de 23,11(0,31), o que indica que as relações sociais no meio acadêmico não são tão ruins, com os estudantes respondendo de forma mais positiva quanto as amizades que possuem no curso, a sensação de isolamento e a vida social. Infere-se que é estatisticamente (Figura 1, item F) diferente a relação entre $1^{\circ}$ e $3^{\circ}$ e o $1^{\circ}$ e $4^{\circ}$ períodos e entre $2^{\circ}$ e $3^{\circ}$ e o $2^{\circ}$ e $4^{\circ}$ períodos, $(\mathrm{p}<0,0001)$. Assim, com o escore maior no $1^{\circ}$ e $2^{\circ}$ períodos, pode-se inferir que as questões sociais são melhores no início da faculdade.

Figura 1 - análise dos domínios do questionário DREEM.

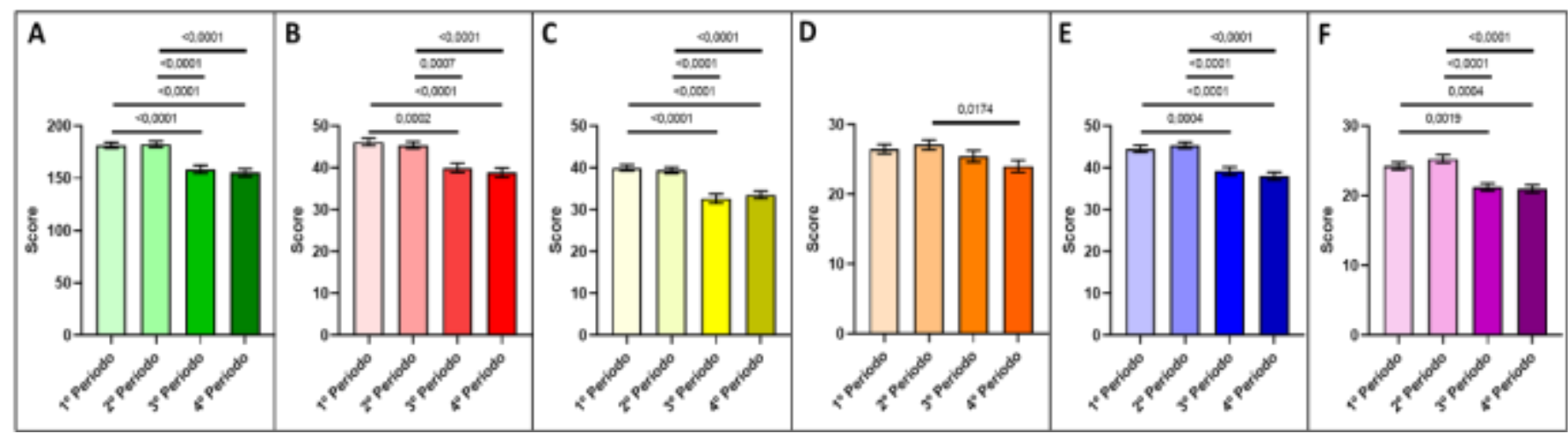

Fonte: Autores (2021).

\subsection{Avaliação da percepção da qualidade de vida}

O questionário WHOQOL-BREF é composto de quatro domínios. O primeiro domínio é o físico em que foi encontrado média de 3,43 (0,04). Esse valor é positivo visto que apresenta-se mais próximo da média superior. Nesse âmbito, é avaliada a questão física dos alunos quanto a presença de dor, desconforto, cansaço e uso de medicamentos. O sono também é investigado de forma indireta a partir do questionamento sobre a energia que o acadêmico possui para realização de atividades. Ocorreu diferença estatística entre $1^{\circ}$ e $3^{\circ}$ e o $1^{\circ}$ e $4^{\circ}$ períodos bem como entre $2^{\circ}$ e $3^{\circ}$ e o $2^{\circ}$ e $4^{\circ}$ períodos, (Figura 2 , item A) ( $\mathrm{p}=0,0001$ ).

Já no quesito psicológico a avaliação média foi de $21,31(0,71)$. Os sentimentos positivos e negativos são abordados nesse domínio, além da autoestima e espiritualidade dos jovens. Todos os períodos demonstraram-se estatisticamente (figura 2, item B) diferentes entre $\mathrm{si},(\mathrm{p}=0,0006)$.

Na dimensão das relações sociais a percepção dos estudantes teve média de 3,79 $(0,05)$. Houve diferença estatística (Figura 2, item C) entre $2^{\circ}$ e $3^{\circ}$ e o $2^{\circ}$ e $4^{\circ}$ períodos, $(p=0,3111)$. Deste modo, a avaliação quanto as relações sociais, suporte emocional e atividade sexual dos acadêmicos foi mais significativa no $2^{\circ}$ período.

A percepção ambiental dos acadêmicos teve média 3,84 $(0,04)$, apresentando uma avaliação mais positiva. Essa percepção envolve as atividades diárias, cuidados da saúde, forma de transporte, a segurança, quantidade de dinheiro necessária, formas de lazer, ambiente físico e oportunidade a novas informações. A perspectiva desses quesitos foi semelhante em todos os 
períodos, pois não houve diferenças estatísticas, (Figura 2, item D), (p=0,6678).

Figura 2 - análise dos domínios do questionário WHOQOL-BREF.

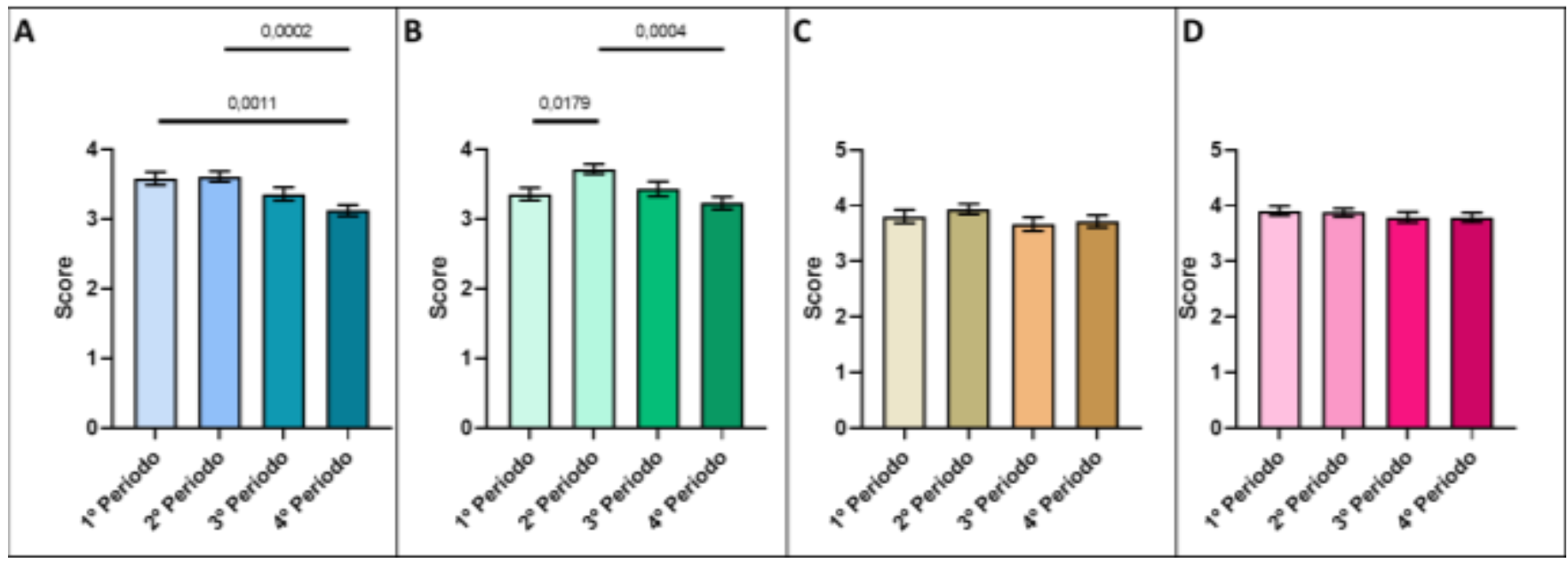

Fonte: Autores (2021).

\section{Discussão}

Assim como em outros trabalhos de Enns (2014), Guimaraes et al. (2015) e Shankar et al. (2013), a adesão a pesquisa foi positiva, haja visto que 77,30\% dos alunos regularmente matriculados em 2019/2 no Ciclo Básico da Universidade de Uberaba responderam o questionário. Uma hipótese para a boa adesão dos alunos foi a utilização do horário e espaço das tutorias proporcionadas pelo curso e o engajamento dos respectivos tutores de ressaltar a importância da participação dos acadêmicos na conquista de possíveis melhorias para o curso. De acordo com o guia prático de avaliação do questionário DREEM, a percepção geral dos discentes sobre o ambiente acadêmico é mais positiva do que negativa. Desse modo, a média geral foi semelhante a outros estudos internacionais e nacionais que utilizaram desse mesmo instrumento (Abraham et al., 2008; Carmody et al., 2009; Enns, 2014). Um estudo indiano de Al-Ayed e Sheik (2008), reitera que o questionário utilizado (DREEM) é um ótimo método para avaliação de escolas médicas, principalmente no ciclo básico em que a maioria das atividades acontecem nas salas de aula. Contudo, o instrumento perde acurácia à medida que os acadêmicos passam de forma rotineira pelas práticas cotidianas com os pacientes, haja visto que as questões avaliadas não comtemplam tão bem tal fase do curso (Soemantri et al., 2010). Nesse sentido, justifica-se o uso de dessa ferramenta nesse estudo.

$\mathrm{Na}$ análise por itens do DREEM adaptado (Tabela 2), foi evidenciado que poucos itens apresentaram pontuação média considerada aspectos positivos do ambiente de ensino. A maioria das questões demonstraram itens que necessitam de otimizações. A menor parte das questões indicaram áreas problemáticas do curso. Isso reflete que assim como em outros estudos realizados no Brasil, o curso de medicina na Universidade de Uberaba, do ponto de vista do ambiente de ensino é considerado positivo. Contudo, é prudente que o estudo em questão seja considerado em planejamentos de possíveis melhorias que possam ser feitas no futuro do curso. 
Tabela 2 - itens do DREEM adaptado com pontuação média maior que 4 e menor que 3.

\begin{tabular}{lcc}
\hline Item & Pontuação média & Domínios \\
\hline Pontos positivos do ambiente de ensino & & SOCIAL \\
\hline 15. Tenho bons amigos (as) na Faculdade & 4,45 & SOCIAL \\
46. Moro em um lugar confortável & 4,61 & SOCIAL \\
\hline Pontos problemáticos do curso & 2,32 & SOCIAL \\
\hline 3. Existe um bom programa de apoio para estudantes estressados & $3,46^{*}$ & 2,80 \\
4. Tenho estado muito cansado (a) para aproveitar este curso (VALOR & 2,61 & APRENDIZADO \\
INVERTIDO) & 2,83 & SOCIAL \\
7. O ensino adotado é frequentemente estimulante & $3,53 *$ \\
14. Raramente me sinto desestimulado nesse curso & ACADÊMICO \\
22. O método de ensino se preocupa em desenvolver minha confiança & APRENDIZADO \\
25. O ensino enfatiza muito o aprendizado de fatos memorizáveis (VALOR & 2,78 & ACADÊMICO \\
INVERTIDO)* & SOCIAL \\
27. Tenho boa capacidade de memória para tudo que preciso & 2,98 & 2,94 \\
28. Raramente me sinto sozinho(a) & $3,36^{*}$ & PROFESSORES \\
48. Os professores dão um bom feedback aos estudantes & APRENDIZADO \\
50. Os estudantes irritam os professores (VALOR INVERTIDO)* & ATMOSFERA \\
\hline
\end{tabular}

Note: *As questões 4, 25, 48 e 50 são negativas e dessa forma foi atribuída pontuação simétrica para sua avaliação. Fonte: Autores.

No que tange o domínio aprendizado, foi possível notar que o primeiro ano do curso ( $1^{\circ}$ e $2^{\circ}$ períodos) tem uma percepção um pouco diferente do segundo ano ( $3^{\circ}$ e $4^{\circ}$ períodos). Apesar de ambos apresentarem médias equivalentes a situações mais positivas que negativas, os $3^{\circ} \mathrm{e} 4^{\circ}$ períodos apresentaram médias inferiores ao $1^{\circ}$ e $2^{\circ}$. Tal fato poderia ser explicado pela grande expectativa do acadêmico após ingressar na faculdade, perpassando pelo primeiro ano como uma fase de adaptação à nova realidade, o que depois, torna-se algo rotineiro e nota-se a maturidade da percepção com o passar do tempo. No mais, outro fato que pode explicar tal diferença estatística é a quantidade de conteúdo e matérias que são adicionadas a partir do terceiro período, bem como o aumento da exigência e nível de complexidade dos assuntos abordados no segundo ano em relação ao primeiro.

Além disso, nesse domínio três questões foram levantadas como problemáticas do curso que são ao estímulo proporcionado pelo ensino, o foco em decorar fatos e uma educação centrada mais no professor do que no aluno. Sob essa ótica, os alunos demonstraram insatisfação com o método de ensinamento oferecido, baseado principalmente na memorização o que para os mesmos é desestimulante, não obstante, essa inferência também foi observada por diversos autores como Enns (2014), Guimaraes et al. (2015), Hasan e Gupta (2013) e Pai et al. (2014). Dessa maneira, o exposto nos mostra que os acadêmicos não se sentem protagonistas do próprio sistema o que para alguns autores são características do sistema de ensino tradicional (Gomes et al., 2009; Guimaraes et al., 2015). Contudo, o curso de medicina da Universidade de Uberaba não tem como metodologia a Aprendizagem Baseada em Problemas (ABP). É possível perceber esforços para que a metodologia ativa seja implantada no ensino médico na Universidade, no entanto, essa pode não estar sendo executada da maneira mais adequada ou ainda é realizada de maneira superficial o que levou os estudantes a terem tal percepção a respeito do ensino.

Em relação ao domínio professores, a pesquisa evidenciou que os professores da instituição estão na direção certa, perante a análise do escore. Essa visão positiva quanto a didática dos preceptores e a relação com os alunos demonstram uma boa relação com os professores. Essa convivência mais satisfatória com os preceptores contribui para um melhor ambiente acadêmico, influenciando na melhor aprendizagem, desempenho e todos os âmbitos da vida do aluno. Assim como no domínio 
aprendizagem, a maturidade e a mudança em relação ao ambiente pré-acadêmico pode ser uma possibilidade de explicação para tal diferença estatística entre primeiro e segundo ano. Também são consideráveis para tal domínio, a relação entre o aumento do número de professores a partir do início do $3^{\circ}$ período, a elevação do nível de dificuldade das disciplinas e exigências por parte dos docentes.

No mais, uma questão referente ao domínio professores recebeu pontuação compatível com problemática do curso. De acordo com a percepção dos alunos do ciclo básico, falta um feedback por parte dos professores. Contudo, o feedback é algo difundido de forma mais clara no ciclo intermediário e internato que correspondem aos acadêmicos do $3^{\circ}$ ao $6^{\circ}$ ano $\left(5^{\circ}\right.$ ao $12^{\circ}$ período). Sendo assim, faz-se importante ações que visem instruir professores do ciclo básico a realizar feedbacks, como a padronização dos itens, instituição de data prévia para acontecimento, apontamento desses pontos por parte da direção com a mesma conotação e importância dada aos períodos posteriores, podem auxiliar na melhoria da percepção dos acadêmicos do ciclo básico do curso sobre esse quesito.

Sobre esse aspecto, Malcom Knowles (Knowles, 1973, como citado em Bellan, 2005) autor da Teoria de Aprendizagem em Adultos propõe um novo modelo de relação entre docentes e discentes. Para o autor, o adulto deve ser sujeito da educação e não objeto dela.

Essa é uma proposta de horizontalidade da relação do binômio docente discente. Nesse sentido, o professor é fundamental na orientação de autogestão e otimização da visão crítica e aprendizado de seu aluno, através de um planejamento educacional e diagnóstico de dificuldades apresentadas, além da corresponsabilização do processo de aprendizagem, com um sistema de avaliação e feedback adequado que vise a melhoria do desempenho do processo como um todo (Bellan, 2005; Chianca-Neves et al., 2020).

Assim como em outros já discutidos, o domínio acadêmico apresentou avaliação compatível com mais aspectos positivos. Os acadêmicos apresentaram uma visão positiva sobre o desempenho acadêmico e a capacidade de aprender e entender o conteúdo. A diferença estatística apresentada entre $1^{\circ}$ e $2^{\circ}$ ano da faculdade pode ser explicada pelo desenvolvimento de experiência do acadêmico sobre o curso como um todo, inclusive sobre o domínio acadêmico. Outro ponto que deve ser levado em consideração é o acúmulo do volume de conteúdo, que aumenta gradualmente a partir do início da fase acadêmica, com aumento da autocobrança e exigências por parte do sistema de ensino.

De acordo com Millan et al. (1999), o acadêmico de medicina passa por três grandes fases no curso, o primeiro contato com a morte no ciclo básico, quando as aulas de anatomia e histologia são as grandes protagonistas; o maior contato com os pacientes que se inicia a partir do ciclo intermediário. Nessa fase, o aluno passa a desenvolver métodos de conversar, avaliar, examinar os pacientes de maneira sistemática, a partir do método clínico; por fim, na última fase do curso, o internato, traz consigo os anseios e vislumbres da carreira médica que está por vir. Essa fase é marcada por insegurança. Diante disso, o estudo em questão trata apenas da fase inicial o que impossibilita a comparação entre tais períodos.

No entanto, dentro dessa dimensão se destacam dois pontos problemáticos. O método de ensino não trabalha a questão pessoal do aluno de forma a estimulá-lo e encorajá-lo, fato percebido e mal avaliado pelos acadêmicos. Além disso, a dificuldade em assimilar grande quantidade de informações e a cobrança em memorizar diversos detalhes causa desagrado e atrapalha no ambiente educacional como um todo. Logo, apesar do estudo tratar apenas do ciclo básico, já nesse ciclo, a percepção dos alunos demonstra déficit de confiança e assim como no domínio aprendizado, frisa a dificuldade em memorizar tudo que é tido como necessário. Nesse sentido, a percepção do acadêmico sobre si mesmo, sofre influência do método adotado, que corrobora para a reafirmação da metodologia tradicional como principal escopo do sistema de ensino do curso de medicina da Uniube (Gomes et al., 2009).

Estudos demonstraram que escolas médicas que traçam o método de ensino a partir da Aprendizagem Baseada em Problemas (ABP), possuem maiores valores de scores da dimensão, acadêmica, professores e aprendizado se comparadas as 
que utilizam a metodologia tradicional (Aghamolaei \& Fazel, 2010; Al-Ayed \& Sheik, 2008; Enns, 2014; Guimaraes et al., 2015; Kiran \& Gowdappa, 2013). Em estudo realizado em duas Universidades do Chile, as pontuações desses quesitos subiram após a transição do ensino tradicional para a ABP (Riquelme et al., 2009). No entanto, apesar de ser utilizado em muitos estudos internacionais, o questionário DREEM não é considerado o melhor instrumento de avaliação para cursos com Aprendizagem Baseada em Problemas, haja visto, a sugestão por parte de alguns autores de que o instrumento não leva em consideração os avanços e atualizações desse sistema (Guimaraes et al., 2015).

A avaliação da percepção do estudante acerca da atmosfera durante as aulas apontou também para mais aspectos positivos do que negativos de maneira geral. Então, os alunos consideraram o ambiente mais tranquilo para as aulas, se sentindo mais confortável para desenvolvimento e interação nas aulas. Essa dimensão é intimamente relacionada a outras como, professores, acadêmico, aprendizado e social. Dessa forma, o ambiente influencia na relação com os preceptores, no desempenho, na forma de ensino e nas relações sociais. A explicação para a diferença encontrada entre os períodos que compõem o estudo tange as mesmas condições correlacionadas as demais dimensões.

Dentro desse domínio, ocorreu uma questão considerada problemática para o curso que é o conflito entre estudantes e professores, visto que os alunos podem se apresentar irritados com os preceptores por questões como o modo de tratamento ou a falta de paciência para explicação. Sob esse aspecto, é comum lugares que seguem o modelo tradicional de ensino apresentarem essa problemática e pode ser atribuída a própria forma metodológica de ensino (Guimaraes et al., 2015). Outras questões como "os professores são autoritários" e "os professores ridicularizam os alunos" são relacionadas à metodologia tradicional, contudo, na Uniube, essas não foram apontadas como problemáticas o que deve ser visto como um ponto positivo no curso.

No âmbito social a análise da percepção apresentou escore compatível com relações sociais não tão ruins. Todavia, assim como em todas as outras dimensões desse questionário, os dois períodos do primeiro ano e os dois períodos do segundo ano do curso se mostram estatisticamente iguais entre si. Seguindo essa lógica, o $1^{\circ}$ e $2^{\circ}$ permutam sua diferença estatística com o $3^{\circ}$ e $4^{\circ}$. Dessa forma, a justificativa para tal não se afasta das anteriormente atribuídas a outros domínios. A pesquisa em questão, realizada através do DREEM, seguiu a mesma linha de análise em ambas as dimensões avaliadas. Sendo assim, é necessário enfatizar a mudança de perspectiva do acadêmico do primeiro ano em relação ao segundo, o que pode ser explicado pela maturidade e experiências adquiridas, bem como aumento considerável das exigências e matérias ao longo de tais períodos. Associado a isso, outro fator importante pode ser atribuído ao estresse e cansaço adquirido ao longo dos semestres que pode refletir de maneira mais clara no domínio social.

Contudo, a dimensão social foi a única dentre as analisadas que apresentou itens considerados positivos. As amizades feitas na faculdade e a moradia ser em um local confortável foram pontos positivos que influenciam em todos os âmbitos da vida do aluno e afeta diretamente sua qualidade de vida. Assim como em um estudo de Guimaraes et al. (2015), realizado no Hospital Dom Malan - Instituto de Medicina Integral Professor Fernando Figueira (HDM/Imip) em Pernambuco, os acadêmicos do curso de medicina da Universidade de Uberaba, referem ter bons amigos e se sentem confortáveis em suas moradias. De acordo com alguns autores, os momentos de estresse, angústias, medos e mudanças estão intimamente relacionados ao sistema de ensino (Almeida \& Cruz, 2010; Anjos \& Aguilar-da-Silva, 2017; Magalhães, 2013). Sob essa ótica, sistemas onde os professores são tutores, contribuem para um ambiente em que as amizades sejam heterogêneas entre os colegas e fortalece a percepção positiva do acadêmico a respeito do seu ambiente de ensino (Almeida \& Cruz, 2010; Magalhães, 2013).

Em relação ao conforto das moradias, de acordo com a avaliação socioeconômica, a maior parte dos alunos moram com os pais ou sozinhos o que pode interferir na análise do conforto de maneira positiva, já que a maior parte dos acadêmicos moram com suas famílias ou não precisam dividir o espaço de moradia com mais ninguém. Outro a ser considerado é que 
$88 \%$ dos alunos pagam a mensalidade integralmente, sem qualquer tipo de bolsa ou desconto, o que pode ser um importante indicador da condição financeira favorável e coerente com a boa avaliação de conforto por parte dos discentes.

No entanto, é também no domínio social, o maior número de tópicos considerados como problemáticas do curso, totalizando 4 nesse quesito. A falta de apoio psicológico, a exaustão acentuada, o desestímulo do curso e o sentimento de isolamento são problemas evidenciados. De acordo com Vogan et al. (2014), as escolas médicas devem ser incentivadas a disponibilizar de forma proativa e precoce um sistema eficaz que se baseie nas necessidades do acadêmico. Para Enns (2014), Fernandes e Guerra (2016) e Guimaraes et al. (2015) as ações de apoio psicossociais devem estar inclusas e fazer parte do sistema de ensino adotado pelas universidades, ser de fácil acesso, ter maciça e ampla divulgação. Além disso, os professores e tutores devem receber informação e assistência adequada, pois a participação destes profissionais são de extrema importância (Enns, 2014).

Nesse sentido, o curso de medicina da Uniube, apesar de contar com um recente programa de apoio psicológico ao aluno, precisa divulgar e difundir de forma mais ativa suas atividades no meio acadêmico. Além disso, ainda conta com tutorias com atividades "mentoring" que integram a carga horária do $1^{\circ}$ ao $12^{\circ}$ período. O sistema de atividades "mentoring" na formação médica, é considerada uma modalidade especial de relação de ajuda em que o tutor (pessoa mais experiente), acompanha, orienta e estimula a partir de sua experiência, conhecimento e comportamento, seu tutorando (discente de medicina), e auxilia o mesmo a desenvolver aspectos não só profissionais, mas também pessoais, no fornecendo subsídios para que esse aluno consiga transpor as adversidades no decorrer da vida acadêmica (Martins \& Bellodi, 2016).

Entretanto, o corpo docente e tutores carecem de informação e assistência adequada para auxiliar na identificação precoce de possíveis situações e pessoas que necessitam do apoio do programa especializado, para que o solicitem de forma adequada e assim possam melhorar a assistência. A percepção dessa problemática por parte dos alunos, apesar da existência de recursos, indica a necessidade de otimização.

Em acordo com outros estudos de Dimoliatis et al. (2010), Dyrbye et al. (2010), Guimaraes et al. (2015) e Oliveira Filho et al. (2005), a análise da percepção do acadêmico de medicina da Uniube demonstra que o aluno tem se sentido desestimulado e cansado demais para aproveitar o curso, além de se sentir sozinho não raramente. De acordo com Dyrbye et al. (2010), o estresse, e a exaustão corroboram para o esgotamento profissional do estudante de medicina e pode refletir no seu desempenho. Alguns estudos discorrem a respeito da influência social e cultural sobre esse domínio e defendem suas nuances para explicar tais problemáticas. Ademais, apesar do DREEM ser considerado livre de influências culturais como foi inicialmente descrito, para Dimoliatis et al. (2010) e Oliveira Filho et al. (2005), esse instrumento não pode ser totalmente isento da tangente desses fatores.

O questionário WHOQOL-BREF adaptado foi aplicado nesta pesquisa, juntamente ao questionário DREEM adaptado, para avaliar a qualidade de vida dos estudantes de medicina. Esse instrumento de coleta de dados possui uma base na subjetividade, sendo a qualidade de vida avaliada pelo próprio sujeito. Além disso, possui caráter transcultural, de maneira que pode ser utilizado como método de pesquisa em diversos meios e com diferentes culturas. Nos últimos anos tem sido muito utilizado para avaliação da qualidade de vida dos estudantes de medicina.

Um estudo realizado em 2013 na Universidade de Brasília (UnB) com o uso do questionário WHOQOL-BREF adaptado demonstrou valores que precisam de melhorias no quesito do domínio físico, o qual foi classificado como o segundo pior avaliado, atrás apenas do domínio psicológico (tabela 3). Nesta pesquisa citada, observou-se comprometimento da capacidade de desempenhar atividades do dia a dia e trabalhar, sono e energia para o dia a dia (Chazan \& Campos, 2013).

Outro estudo realizado em 2016, em uma universidade localizada na Arábia Saudita, demonstrou a elevada prevalência da qualidade de sono ruim entre os estudantes de medicina e a sua significativa associação com o estresse. Atribuise a essa situação o fato de que os acadêmicos do curso de medicina adquirem um estilo de vida com redução das horas de 
sono devido a extensa carga horária, cobranças frequentes e pela relação de competitividade entres os colegas de curso, de forma que passam a viver com índices altos de estresse e baixos de energia (Almojali et al., 2017; Zhang et al., 2012). Assim, uma pesquisa feita em 2020 no curso de Medicina de uma instituição pública de Goiás utilizando o questionário WHOQOLBREF correlacionou as horas de sono com a qualidade de vida demonstrando que alunos com maior horas de sono apresentaram maior qualidade de vida em todos os domínios (Miranda et al., 2020).

Em consonância com o citado acima, no presente estudo o domínio físico se encontra entre aqueles passíveis de melhorias, sendo o pior avaliado. De acordo com os dados apresentados, é possível levantar a hipótese de que devido a extensa carga horária e exaustiva cobrança do curso de Medicina, o manejo do tempo do estudante entre as disciplinas, o estudo, as atividades físicas e o lazer ficam difíceis. Assim, o acadêmico encontra-se em um constante ciclo vicioso de privação de sono, cansaço e falta de energia, esses aspectos contribuindo para reduzir a qualidade de vida do estudante. $\mathrm{O} 4^{\circ}$ período foi aquele em que o domínio físico recebeu sua menor pontuação, isso pode ser explicado pelo fato de ser o de maior carga horária e o de maior número de matérias do ciclo básico, o que influencia diretamente nos tópicos avaliados neste domínio.

Outra semelhança entre este estudo e o realizado em 2013 na UnB é em relação ao domínio psicológico, o qual sofreu, em ambos, diferenças estatisticamente significantes entre as variáveis investigadas (Chazan \& Campos, 2013). Também, obteve-se esse resultado em um estudo realizado na China Medical University em 2011 com o uso do questionário WHOQOLBREF adaptado (Zhang et al., 2012). Diante de tais dados, pode-se entender que a mudança de um período para o outro implica em alterações de carga horária, professores, disciplinas, de maneira a trazer sentimentos positivos ou negativos para o estudante. Por exemplo, neste estudo o fato do $2^{\circ}$ período ter obtido a menor nota no domínio psicológico pode ser justificado pela inserção de matérias de maior complexidade na grade curricular, o que gera sentimentos de ansiedade e estresse entre os acadêmicos.

Tabela 3 - itens do WHOLQOL-BREF adaptado com pontuação média maior que 4 e menor que 3.

\begin{tabular}{|c|c|c|c|}
\hline & Item & $\begin{array}{l}\text { Pontuação } \\
\text { média }\end{array}$ & Domínios \\
\hline \multicolumn{4}{|c|}{ Pontos positivos da qualidade de vida dos estudantes } \\
\hline & Como você avaliaria sua qualidade de vida? & 4,02 & - \\
\hline & 15. Quão bem você é capaz de se locomover? & 4,41 & Físico \\
\hline mora? & 23. Quão satisfeito(a) você está com as condições do local onde & 4,45 & Ambiente \\
\hline saúde? & 24. Quão satisfeito(a) você está com o seu acesso aos serviços de & 4,19 & Ambiente \\
\hline \multicolumn{4}{|c|}{ Pontos negativos da qualidade de vida dos estudantes } \\
\hline & 16. Quão satisfeito(a) você está com o seu sono? & 2,69 & Físico \\
\hline como ma & $\begin{array}{l}\text { *26. Com que frequência você tem sentimentos negativos tais } \\
\text { a humor, desespero, ansiedade, depressão? } \\
\text { (*PONTUAÇÃO INVERTIDA) }\end{array}$ & $3,42 *$ & Psicológico \\
\hline
\end{tabular}

Note: *A questão 26 é negativa e dessa forma foi atribuída pontuação simétrica para sua avaliação. Fonte: Autores (2021). 
Já o domínio relações sociais obteve a menor nota no $3^{\circ}$ período, esse fato pode ser devido à quantidade de matéria que é inserida no currículo em relação ao período anterior, o que acarreta em maior tempo de estudo e menos tempo em eventos e interações sociais. Sendo assim, essa pior nota em relação as interações sociais e pessoais desse período apresenta uma correlação com menor qualidade de vida quanto ao domínio social. Semelhante ao coletado neste estudo, ocorreu em um realizado na China Medical University, no qual os acadêmicos do $3^{\circ}$ ano possuíam as menores pontuações no domínio social devido, justamente, a maior complexidade das disciplinas, grande pressão sob os estudantes e menor tempo disponível para o lazer (Zhang et al., 2012).

O domínio que apresenta maior média geral é o referente ao ambiente. Ciente de que tal domínio aborda condições de moradia, meios de transporte e acesso aos serviços de saúde, é compreensível sua maior média em relação aos demais. Uma vez que se trata de um curso integral e de elevado custo, de maneira que a grande maioria dos acadêmicos possui boa condição econômica e depende da família para concluir o curso. Esse domínio é o apontado com maior sensibilidade as variações socioeconômicas (Chazan \& Campos, 2013).

Pode-se inferir que as médias baixas nos quatro domínios são desdobramentos da extensa grade curricular, da carga horária excessiva e da cobrança dos professores. Nesse sentido, a saúde mental dos estudantes de medicina tem se tornado alvo de inúmeras pesquisas. Dentre os problemas psicológicos, se destacam instabilidade emocional, falta de energia e depressão. Quanto às habilidades sociais, acentuam-se baixa autoafirmação e alta expressão de sentimentos negativos (Querido et al., 2016; Erschens et al., 2018). Um estudo realizado na UMC em São Paulo, utilizando o WHOQOL abreviado, avaliou o estresse nos estudantes de Medicina e citou como as principais causas do estresse o excesso de disciplinas, a falta de lazer e os distúrbios do sono. Lima et al (2016) identificaram que as causas do estresse são a iminente entrada no mercado de trabalho, o número aumentado de informações a aprender; os desafios para conciliar o tempo entre as tarefas domésticas e atividades de lazer, as questões mais íntimas consigo mesmo e família e problemas financeiros.

Independentemente dos fatores estressantes a que são submetidos, alguns estudantes conseguem elaborar estratégias para lidar com essas situações degradantes. Outros, porém, não conseguem sozinhos visualizar formas de passar por esses momentos difíceis, e esses são os mais propensos a apresentar dificuldade em levar adiante o curso mantendo uma boa saúde mental. Uma proposta utilizada em diversas faculdades de Medicina, inclusive na faculdade em que esse estudo foi realizado, é o programa de tutoria (Zonta et al., 2006).

A fim de ofertar uma formação integral ao estudante, com intuito de auxiliar em sua trajetória no âmbito acadêmico, algumas universidades desenvolveram redes de suporte, com o oferecimento de serviços de saúde, como consultas médicas, terapias psicológicas, auxílio pedagógico e assistência social (Martins \& Bellodi, 2016). Dessa forma, a tutoria pode ser vista como uma forma de auxiliar os estudantes que obtiveram baixos scores nos questionários aplicados. Na educação de cursos da área da saúde, a tutoria é importante sobretudo para aprimorar o suporte acadêmico, reduzir o risco de burn-out e promover o desenvolvimento de relações dentro da profissão e da satisfação com a futura carreira (Alpes \& Wolf, 2018).

Além da tutoria, outras estratégias devem ser adotadas pelos acadêmicos com o intuito de aliviar o estresse diário e melhorar o desempenho no curso. Um estudo mostrou que os estudantes de medicina utilizam mecanismos de defesa para aliviar moderadamente a tensão e o estresse causados pelo curso. Uns optam por isolamento afetivo a fim de aproveitar o pouco tempo livre para descanso, outros procuram ter relacionamentos interpessoais saudáveis e praticar exercícios físicos ao ar livre sempre que possível. Alimentar-se adequadamente foi fator comum entre ambos os grupos (Benevides-Pereira \& Gonçalves, 2009; Bassols, 2014; Vargas et al., 2017). Uma das estratégias mais assinaladas pelos estudantes é o suporte social, a valorização das relações interpessoais como uma forma de lidar com o estresse a que estão submetidos. Isto aponta que o modo como é promovida a integração acadêmica pode guardar relações com o nível de bem-estar do estudante (Barros \& Wilhelm, 2020). 


\section{Conclusão}

A partir da análise de dados coletados através dos questionários DREEM e WHOQOL-BREF foi possível avaliar a percepção do ambiente acadêmico e a qualidade de vida dos estudantes do ciclo básico do curso de medicina da Universidade de Uberaba.

O estudo demonstra que a percepção dos discentes em relação ao ambiente de ensino foi mais positiva do que negativa. Porém, poucos itens apresentaram pontuação média considerados aspectos positivos. Assim, a maioria das questões apresentou itens que necessitam de melhorias, como os domínios social, aprendizado, acadêmico, professores e atmosfera.

A qualidade de vida dos estudantes foi analisada pelo estudo e apresentou pontos positivos quanto aos aspectos físicos e ambientais. Os pontos negativos da qualidade de vida foram as questões físicas e psicológicas. O domínio físico possui a pior avaliação devido a extensa carga horária e exaustiva cobrança do curso, sendo passível de melhorias.

Contudo, o tema ainda carece de estudos. Pesquisas mais abrangentes que incluam os demais ciclos do ensino médico, poderiam contribuir de forma positiva para o aprimoramento das intervenções com intenção melhorar o ambiente de educacional. Outro ponto relevante para colaborar com o conhecimento sobre essa temática, seriam estudos com base no acompanhamento periódico dos alunos. Assim, possibilitaria identificar possíveis mudanças nos parâmetros de respostas dos estudantes com o decorrer dos períodos e guiar otimizações direcionadas a cada ciclo do curso.

\section{Referências}

Abraham, R., Ramnarayan, K., Vinod, P., \& Torke, S. (2008). Students' perceptions of learning environment in an Indian medical school. BMC medical education, 8(20). https://doi.org/10.1186/1472-6920-8-20

Aghamolaei, T., \& Fazel, I. (2010). Medical students' perceptions of the educational environment at an Iranian Medical Sciences University. BMC medical education, 10(87). https://doi.org/10.1186/1472-6920-10-87

Al-Ayed, I. H., \& Sheik, S. A. (2008). Assessment of the educational environment at the College of Medicine of King Saud University, Riyadh. Eastern Mediterranean health journal, 14(4), 953-959. https://applications.emro.who.int/emhj/1404/14_4_2008_0953_0959.pdf

Almeida, L. S., \& Cruz, J. F. A. (2010). Transição e adaptação académica: reÀexões em torno dos alunos do $1^{\circ}$ ano da Universidade do Minho. Ensino superior em mudança: tensões e possibilidades: actas do Congresso Ibérico. Portugal, 429-440. http://hdl.handle.net/1822/11543

Almojali, A. I., Almalki, S. A., Alothman, A. S., Masuadi, E. M., \& Alaqeel, M. K. (2017). The prevalence and association of stress with sleep quality among medical students. Journal of epidemiology and global health, 7(3), 169-174. https://doi.org/10.1016/j.jegh.2017.04.005

Alpes, M. F., \& Wolf, A. E. (2018). Tutoria acadêmica ("mentoring”): relato de experiência de um tutorado à tutor. Revista Extensão em Foco, 16, 90-98. http://dx.doi.org/10.5380/ef.v0i16.55133

Anjos, D. R. L. dos, \& Aguilar-da-Silva, R. H. (2017). Questionário de Vivências Acadêmicas (QVA-R): avaliação de estudantes de medicina em um curso com currículo inovador. Avaliação: Revista da Avaliação da Educação Superior, 22(1), 105-123. https://doi.org/10.1590/S1414-40772017000100006

Bakhshialiabad, H., Bakhshi, G., Hashemi, Z. Amirhosein Bakhshi, A., \& Abazari, F. (2019). Improving students' learning environment by DREEM: an educational experiment in an Iranian medical sciences university (2011-2016). BMC Med Educ, 19(397). https://doi.org/10.1186/s12909-019-1839-9

Barros, M. S. P., \& Wilhelm, F. A. (2020). Estratégias de enfrentamento do estresse utilizadas por jovens universitários no extremo norte do país. Revista Brasileira de Iniciação Científica, 7(1), 100-117. https://periodicos.itp.ifsp.edu.br/index.php/IC/article/view/1567/1199

Bassols, A. M. S. (2014). Estresse, ansiedade, depressão, mecanismos de defesa e coping dos estudantes no início e no término do curso de medicina da Univrsidade Federal do Rio Grande do Sul. Tese de Doutorado, Universidade Federal do Rio Grande do Sul, Porto Alegre, RS, Brasil. Disponível: https://www.lume.ufrgs.br/bitstream/handle/10183/104141/000938859.pdf?sequence=1\&isAllowed=y.\%20Acesso\%20em\%2010.04.2020

Bellan, Z. S. (2005). Andragogia em ação (1ed). SOCEP.

Benevides-Pereira, A. M. T., \& Gonçalves, M. B. (2009). Transtornos emocionais e a formação em medicina: um estudo longitudinal. Revista Brasileira de Educação Médica, 33(1), 10 - 23. https://doi.org/10.1590/S0100-55022009000100003

Borine, R. C. C., Wanderley, K. S., \& Bassitt, D. P. (2015). Relação entre qualidade de vida e o estresse em acadêmicos da área da saúde. Estudos Interdisciplinares em Psicologia, 6(1), 100-118. http://pepsic.bvsalud.org/scielo.php?script=sci_arttext\&pid=S2236-64072015000100008\&lng=pt\&tlng=pt

Carmody, D. F., Jacques, A., Denz-Penhey, H., Puddey, I., \& Newnham, J. P. (2009). Percepetions by medical students of their educational environment for obstetrics and gynaecology in metropolitan and rural teaching sites. Medical Teacher, 31(12), 596-602. https://doi.org/10.3109/01421590903193596

Chazan, A. C., \& Campos, M. R. (2013). Qualidade de Vida de Estudantes de Medicina medida pelo WHOQOL-bref - UERJ, 2010. Revista Brasileira de Educação Médica, 37(3), 376-384. https://doi.org/10.1590/S0100-55022013000300010 
Chianca-Neves, M. G. B., Lauer-Leite, I. D., \& Priante, P. T. (2020). As concepções de preceptores do SUS sobre metodologias ativas na formação do profissional da saúde. Educação em Revista, 36. https://doi.org/10.1590/0102-4698207303

Costa, M. de, \& Moreira, Y. B. (2016). Saúde mental no contexto universitário. Blucher Design Proceedings, 2(10), 73-79. http://dx.doi.org/10.5151/desprosed2016-009

Cunha, D. H. F., Moraes, M. A., Benjamin, M. R., \& Santos, A. M. N. (2017). Percepção da qualidade de vida e fatores associados aos escores de qualidade de vida de alunos de uma escola de medicina. Jornal Brasileiro de Psiquiatria, 66(4), 189-196. https://doi.org/10.1590/0047-2085000000170

Dimoliatis, I. D., Vasilaki, E., Anastassopoulos, P., Ioannidis, J. P., \& Roff, S. (2010). Validation of the Greek translation of the Dundee Ready Education Environment Measure (DREEM). Education for health (Abingdon, England), 23(1), 348.

Dyrbye, L. N., Power, D. V., Massie, F. S., Eacker, A., Harper, W., Thomas, M. R., Szydlo, D. W., Sloan, J. A., \& Shanafelt, T. D. (2010). Factors associated with resilience to and recovery from burnout: a prospective, multi-institutional study of US medical students. Medical education, 44(10), 1016-1026. https://doi.org/10.1111/j.1365-2923.2010.03754.x

Enns, S. C. (2014). Avaliação da percepção do ambiente de ensino e sua relação com a qualidade de vida em estudantes de medicina. Tese de Doutorado, Universidade de São Paulo, São Paulo, SP, Brasil. Disponível: https://www.teses.usp.br/teses/disponiveis/5/5169/tde-09022015-142219/pt-br.php

Erschens, R., Herrmann-Werner, A., Keifenheim, K. E., Loda, T., Bugaj, T. J., Nikendei, C., Lammerding-Köppel, M., Zipfel, S., \& Junne, F. (2018). Differential determination of perceived stress in medical students and high-school graduates due to private and training-related stressors. PloS one, 13(1), e0191831. https://doi.org/10.1371/journal.pone.0191831

Feodrippe, A. L. O., Brandão, M.C.F., \& Valente, T.C.O. (2013). Qualidade de vida de estudantes de Medicina: uma revisão. Revista Brasileira de Educação Médica, 37(3), 418-428. https://doi.org/10.1590/S0100-55022013000300014

Ferentz, L. M. S. (2017). Análise da Qualidade de Vida pelo método WHOQOL-Bref: estudo de caso na cidade de Curitiba, Paraná. Revista Estudo \& Debate, 24(3), 116-134. http://dx.doi.org/10.22410/issn.1983-036X.v24i3a2017.1359

Fernandes, A. A., \& Guerra, L. M. B. (2016). Relatório do $2^{o}$ simpósio de avaliação da educação superior. https://www.uern.br/controledepaginas/aaieventos/arquivos/3970relata\%E2\%80\%9Crio_avalies_2016.pdf

Gomes, R., Brino, R. F., Aquilante, A. G., \& Avó, L. R. S. (2009). Aprendizagem Baseada em Problemas na formação médica e o currículo tradicional de Medicina: uma revisão bibliográfica. Revista brasileira de educação médica, 33(3), 444-451. https://doi.org/10.1590/S0100-55022009000300014

Guimaraes, A. C., Falbo, G. H., Menezes, T., \& Falbo, A. (2015). Percepção do Estudante de medicina acerca do ambiente Educacional utilizando o DREEM. Revista Brasileira de Educação Médica, 39(4), 517-526. https://doi.org/10.1590/1981-52712015v39n4e01062014

Hasan, T., \& Gupta, P. (2013). Assessing the learning environment at Jazan Medical School of Saudi Arabia. Medical teacher, 35 (Suppl 1), $890-896$. https://doi.org/10.3109/0142159X.2013.765546

Ibrahim, A. K., Kelly, S. J., Adams, C. E., \& Glazebrook, C. (2013). A systematic review of studies of depression prevalence in university students. Journal of Psychiatric Research, 47(3), 391-400. https://doi.org/10.1016/j.jpsychires.2012.11.015

Kiran, H. S., \& Gowdappa, B. H. (2013). "DREEM" comes true - Students' perceptions of educational environment in an Indian medical school. Journal of postgraduate medicine, 59(4), 300-305. https://doi.org/10.4103/0022-3859.123159

Lima, R. L. de, Soares, M. E. C., Prado, S. N. do, \& Albuquerque, G. S. C. de. (2016). Estresse do estudante de Medicina e Rendimento Acadêmico. Revista Brasileira de Educação Médica, 40(4), 678-684. https://doi.org/10.1590/1981-52712015v40n4e01532015

Magalhães, M. O. (2013). Sucesso e fracasso na integração do estudante à universidade: um estudo comparativo. Revista Brasileira de Orientação Profissional, 14(2), 215-226. http://pepsic.bvsalud.org/scielo.php?script=sci_arttext\&pid=S1679-33902013000200007\&lng=pt\&tlng=pt

Martins, A. F., \& Bellodi, P. L. (2016). Mentoring: uma vivência de humanização e desenvolvimento no curso médico. Interface, 20(58), 715-726. https://doi.org/10.1590/1807-57622015.0432

McAleer, S., \& Roff, S. (2001). A practical guide to using the Dundee Ready Education Environment Measure (DREEM). In J. M. Genn (Ed.), Curriculum, environment, climate, quality and change in medical education: A unifying perspective. AMEE Education Guide, (23), 29-33. https://www.scirp.org/(S(vtj3fa45qm1ean45vvffcz55))/reference/ReferencesPapers.aspx?ReferenceID=799758

Mendonça, A. M. M. C., Gêda, T. F., Guimarães, J. E., Mendes, C. O., Manna, T. B. F., \& Monteiro, E. M. (2019). Perspectiva dos Discentes de Medicina de uma Universidade Pública sobre Saúde e Qualidade de Vida. Revista Brasileira de Educação Médica, 43(1), 228-235. https://doi.org/10.1590/19815271v43suplemento1-20190043

Millan, L. R., De Marco, O. L. N., Rossi, E., \& Arruda, P. C. V. de. (1999). O universo psicológico do futuro médico: vocação, vicissitudes e perspectivas. Casa do Psicólogo.

Miranda, I. M. M., Tavares, H. H. F., Silva, H. R. S. da, Braga, M. S., Santos, R. O., \& Guerra, H. S. (2020). Quality of Life and Graduation in Medicine. Revista Brasileira de Educação Médica, 44(3), 1-8. https://doi.org/10.1590/1981-5271v44.3-20200068.ING

Olivares, A., Bonito, J., \& Silva, R. (2015). Qualidade de vida no trabalho dos médicos da atenção básica no estado de Roraima (Brasil). Psicologia, Saúde \& Doenças, 16(1), 100-111. http://dx.doi.org/10.15309/15psd160210 
Research, Society and Development, v. 10, n. 13, e125101320841, 2021

(CC BY 4.0) | ISSN 2525-3409 | DOI: http://dx.doi.org/10.33448/rsd-v10i13.20841

Oliveira Filho, G. R., Vieira, J. E., \& Schonhorst, L. (2005). Psychometric properties of the Dundee Ready Educational Environment Measure (DREEM) applied to medical residents. Medical teacher, 27(4), 343-347. https://doi.org/10.1080/01421590500046387

Pai, P. G., Menezes, V., Srikanth, Subramanian, A. M., \& Shenoy, J. P. (2014). Medical students' perception of their educational environment. Journal of clinical and diagnostic research: JCDR, 8(1), 103-107. https://doi.org/10.7860/JCDR/2014/5559.3944

Pereira, H. P., Lopes, D. G., Gonçalves, M. C., \& Vasconcelos-Raposo, J. J. (2017). Revista iberoamericana de psicología del ejercicio y el deporte, 12(2), 297305. https://www.redalyc.org/articulo.oa?id=311151242013

Peres, R. S., Santos, M. A., \& Coelho, H. M. B. (2004). Perfil da clientela de um programa de pronto-atendimento psicológico a estudantes universitários. Psicologia em Estudo, 9(1), 47-54. https://doi.org/10.1590/S1413-73722004000100007

Querido, I. A., Naghettini, A. V., Orsini, M. R. de C. A., Bartholomeu, D., \& Montiel, J. M. (2016). Fatores associados ao estresse no internato médico. Revista Brasileira de Educação Médica, 40(4), 565-573. https://doi.org/10.1590/1981-52712015v40n4e00072015

Riquelme, A., Oporto, M., Oporto, J., Mendez, J. I., Viviani, P., Salech, F., Chianale, J., Moreno, R. \& Sánchez, I. (2009). Measuring students perception of the educational climate of the new curriculum at the Pontíficia Universidad Católica de Chile: performance of the

Sarwar, S., Aleem, A., \& Nadeem, M. A. (2019). Health Related Quality of Life (HRQOL) and its correlation with academic performance of medical students. Pakistan journal of medical sciences, 35(1), 266-270. https://doi.org/10.12669/pjms.35.1.147

Spanish translation of the Dundee Ready Education Environment Measure (DREEM), Education for Health Change in Learning \& Practice, $22(1), 112$. https://www.educationforhealth.net/article.asp?issn=1357-6283; year=2009; volume=22;issue=1; ;page=112; epage=112; aulast=Riquelme

Shankar, P. R., Dubey, A. K., \& Balasubramanium, R. (2013). Students' perception of the learning environment at Xavier University School of Medicine, Aruba Journal of Educational Evaluation for Health Professions, 10(8), 1-5. https://doi.org/10.3352/jeehp.2013.10.8

Soemantri, D., Herrera, C., \& Riquelme, A. (2010). Measuring the educational environment in health professions studies: a systematic review. Medical teacher, 32(12), 947-952. https://doi.org/10.3109/01421591003686229

The World Health Organization Quality of Life assessment (WHOQOL): position paper from the World Health Organization. (1995). Social science \& medicine, 4l(10), 1403-1409. https://doi.org/10.1016/0277-9536(95)00112-k

Vargas, M., Talledo-Ulfe, L., Heredia, P., Quispe-Colquepisco, S., \& Mejia, C. R. (2018). Influence of habits on depression in the Peruvian medical student: Study in seven administrative regions. Revista Colombiana de Psiquiatria, 47(1), 32-36. https://doi.org/10.1016/j.rcpeng.2017.12.009

Vogan, C. L., McKimm, J., Silva, A. L. da, \& Grant, A. (2014). Twelve tips for providing effective student support in undergraduate medical education. Medical teacher, 36(6), 480-485. https://doi.org/10.3109/0142159X.2014.907488

Yoo, D. M., \& Kim, D. H. (2019). The relationship between students' perception of the educational environment and their subjective happiness. BMC medical education, 19(1), 409. https://doi.org/10.1186/s12909-019-1851-0

Zhang, Y., Qu, B., Lun, S., Wang, D., Guo, Y., \& Liu, J. (2012). Quality of life of medical students in China: a study using the WHOQOL-BREF. PloS one, 7(11), e49714. https://doi.org/10.1371/journal.pone.0049714

Zonta, R., Robler, A. C. C., \& Grosseman, S. (2006). Estratégias de enfrentamento do estresse desenvolvidas por estudantes de Medicina da Universidade Federal de Santa Catarina. Revista brasileira de educação médica, 30(3), 147-153. https://doi.org/10.1590/S0100-55022006000300005 